\title{
GSM Quality Of Service Performance IN ABUjA, NigERIA
}

\author{
Alabi I Kehinde, Sagir Lawan. Fatai O Adunola, and Alabi I Isaac \\ Communication Research Cluster Electrical Electronic Engineering Nigerian Defence \\ Academy Kaduna
}

\begin{abstract}
There has been tremendous growth in Global System for Mobile (GSM) services in Nigeria in the last two decade. The rapid development of GSM telecommunication industries have given rise to need for how the GSM services are delivered to customers efficiently. This paper is on GSM quality of service (QoS) performance in, Abuja Nigeria. The study investigates network transmission impairment and offers some useful remedies. The method involved use of Sony Ericson W-995 phone to gather data on physical network impairments in selected densely populated areas of Abuja. The data obtained were from four major GSM service providers MTN, Etisalat, Glo and Airtel. Assessment in terms of Key Performance Indicator (KPI) using Transmission Environment Monitory System (TEMS) Discovery professional software carried out on the networks under test. The results obtained from the analysis indicated that QoS performance of Airtel is slightly better than the other three GSM services providers tested within Nyanyan, Gwagwalada, and Wuse areas in Abuja.
\end{abstract}

\section{KEYWORDS}

GSM, QoS, Wireless Network, Mobile Network, KPI

\section{INTRODUCTION}

The GSM system is the most widely used cellular mode of communication used in Nigeria today. The GSM service has been successful for a variety of reason which include portable service while on the move and roaming capabilities. The era of GSM network service in Nigeria started in August, 2001 [Hassan et al, 2009]. This era has completely changed the face of every aspect human life in Nigeria, today there over 147,398,854 GSM subscribers across Nigeria [Nigeria Telecommunication Service Sector Report, 2016].

Despite all the aforementioned advantages of GSM, it has some challenges that make it difficult to access for the emerging robust applications. One of the biggest problems is poor network performance. In spite of the low level in QoS performance experienced in many part of the country, the GSM subscription is rapidly increasing in Nigeria. The application of GSM generates high traffic in which several multimedia components in form of speech, video, and other forms of data are multiplexed. These voluminous data cannot be effectively handled due to high variable bit rates. The bandwidth offered is rigid and cannot be dynamically varied as needed. Conversely, GSM capabilities have been improved considerably with the development of High-Speed CircuitSpeed Data (HSCSD), General Packet Radio Service (GPRS), and Enhance Data rate for GSM Evolution (EDGE). Upon this development there are still some shortcomings in the network performance. The introduction of $2.5 \mathrm{G}$ and $3 \mathrm{G}$ which are designed to handle some of these problems but the Operators still experience network failures on some occasion. Fiber optics is one of the widely used medium for data transmissions by the GSM providers. However, frequent vandalizations of fiber networks which link the cell sites severely affect GSM network QoS performance. Thus, there are need for protection of this critical network infrastructure from willful damage by vandals and construction activities. 


\section{Key Performance Indicator For Qos ASSESSMent}

Key performance indicator is one of the measures used to evaluate the services provided by GSM networks. This is accomplished by monitoring the effectiveness of some network impairments. QoS in (S Lawan 2015) is defined as a set of specific requirements provided by a network necessary to achieve the required functionality of service. According to (V.E Idigo, 2012), the Nigerian Communication Commission (NCC) in 2007 held a public forum in the use of KPI to identify issues affecting (QoS). KIP is also applied to improve the unacceptable QoS delivered on the various networks. Network impairments such as distortion, noise and congestion limits transmission effectiveness. (Kollor, 2008) stated that KPIs on which the GSM network were tested according includes Call Set Up Success Rate (CSSR), Call Drop Rate (CDR), Call Completion Success Rates (CCSR), Handover Success Rates (HSR) and Traffic Channel Congestion rate (TCHR). Others are Handover Success Rate (HOSR), Network congestion, Stand-Alone Dedicated Control Channel (SDCCH) Congestion Rate and Dedicated Control Channel Congestion (DCCHC). According to Omotoye et al, (2014) monitoring tools of the GSM network performance may involve different events and subsystem that are sometimes refers to as statistics and traffic measurement subsystem (STS). In some case a common, dedicated, traffic and pulse code modulation (PCM) channels are make use of for the assignment for the incoming or outgoing network perforce service request.

\section{Results Of Four Gsm Network Providers Performance In ABUJA}

Bench marking test on the performance of four GSM network providers namely: Airtel, MTN, GLO and ETISALAT was carried out on some selected Mobile Station (MS) in Abuja. The performance was described according to different RF measurements and a comparative analysis was carried out. A convenient and powerful phone network software known as TEMS Pocket Professional (w995 Phone) was the equipment used for obtaining relevant data. This software allows for great flexibility in network monitoring and promotes multiple uses of the same data. The area of study covers most parts of Abuja which was subdivided into clusters. This cluster includes Kubwa, Airport, Nyanyan, Jabi, Central Area Business District and Wuse/maitama. The subdivision in to clusters is necessary because Abuja City possesses the high and large number of networks of different kinds.

\subsection{Map Of Geographical Area Under Test}

Bench marking test carried out on both $2 \mathrm{G}$ and $3 \mathrm{G}$ technology across the Four Major Telecom service provider, the map of the geographical area is as shown in Figure 1.

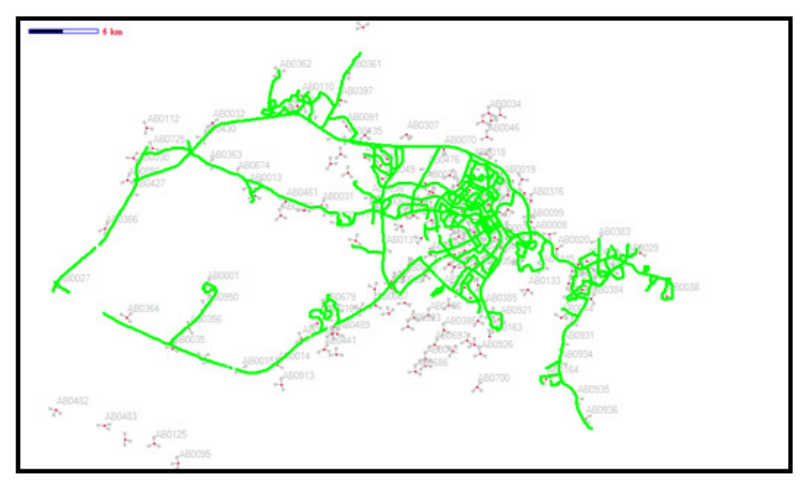

Figure 1: Abuja Map of Geographical Area under Test 


\subsection{Performance Of Airtel 2G IDLE MODE}

Figure 2 shows the Airtel performance level that had been plotted for 2G IDLE MODE. From the diagram the overriding colour is the sky blue which indicate $(-65,0) \mathrm{dB}$ coordinate. The counts and percentage of the cluster are (28491 and 69.19\% respectively. This pointed out that the received signal for AIRTEL was at its best along the routes illustrated in the diagram. It was discovered that network performance of those areas that are dotted with dark green colours are $45.62 \%$ lower than the required quality signal.

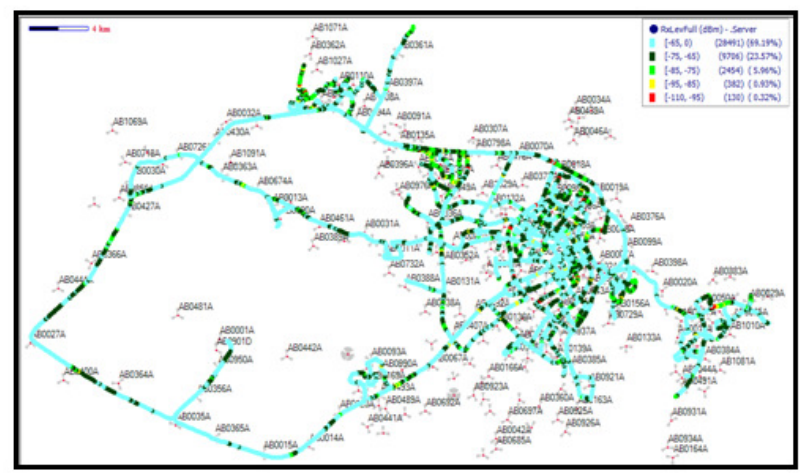

Figure 2: Airtel performance level plotted for 2G IDLE MODE.

\subsection{Airtel And Mtn Performance 2g Idle Mode}

Figure 3 compare the permance of AITEL and MTN network services along the area under test. It was obseved that Airtel coverage has no bad patches when compared with MTN as more of (-95 to -85$) \mathrm{dBm}$ was recorded for MTN.

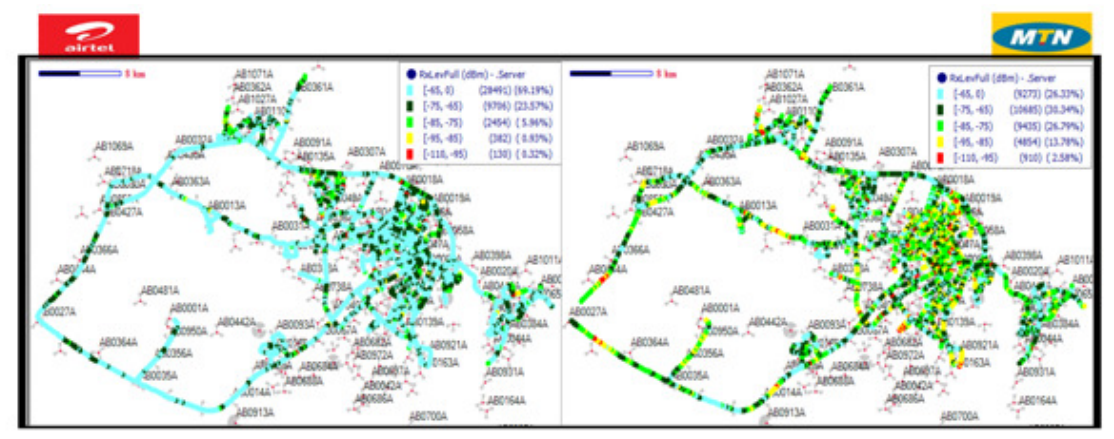

Figure 3: Performance of AITEL and MTN network services

\subsection{AIRTEL And GLO Performance 2G IDLE MODE}

Airtel coverage was observed to be having better $-65 \mathrm{dbm}$ count when compared with GLO as illustrated in Figure 4. The count for Airtel is 28491 amounting to $69.19 \%$, while, for Glo count is slightly lower, recoded as 25565 amounting to $60.65 \%$. 


\section{P} glo

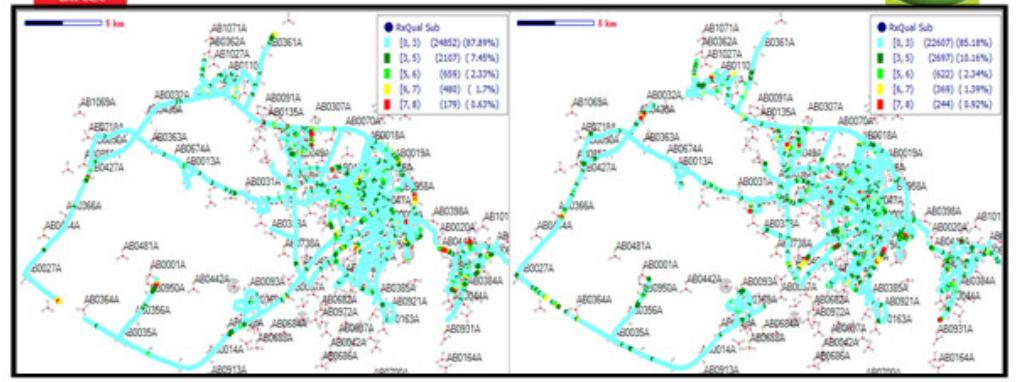

Figure 4: Performance of AITEL and Glo network services

\subsection{AIRTEL And Etisalat Performance 2G IDLE MODE}

From figure 5, the map plotted for Etisat contained more yellow $(-95,-85)$ with count of 2881 amounting to $8.05 \%$, at the same time Aritel recorded count of 362, amounting to $0.93 \%$. Thus, Airtel coverage was observed to be having no bad patches when compared with ETISALAT.

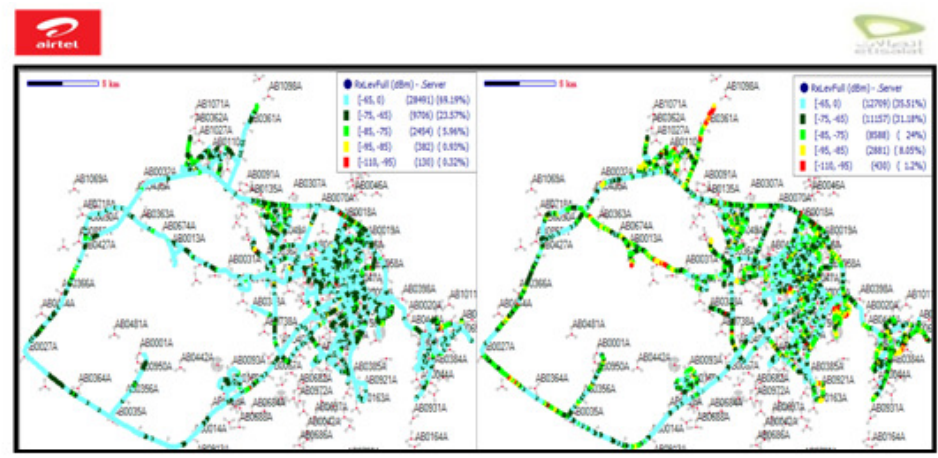

Figure 5: Performance of AITEL and Etisalat network services

\section{Plot For Airtel 2G Dedicated Mode}

An analysis of the data by $2 \mathrm{G}$ dedicated mode level shows that higher levels of throughput correspond to higher levels of network QoS for Airtel throughout the test. Figure 6 shows Airtel dominance performance of $(0,3)$ counting 24852 amounting to $87.89 \%$.

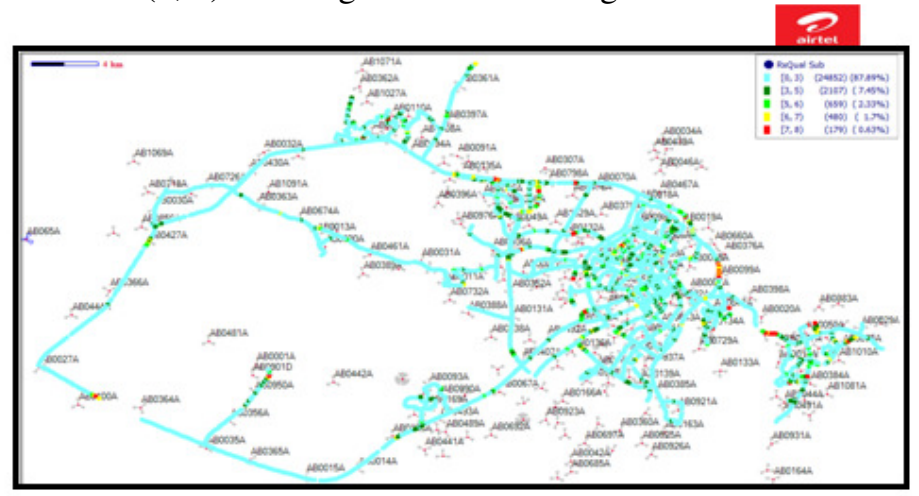

Figure 6: Performance of AITEL network services for 2G Dedicated Mode 


\subsection{Plot For Airtel ANd MTN 2G Dedicated Mode}

A steady but significant rise can be seen in the percentage of the network QoS between Airtel and MTN for dedicated 2G services as own in Figure 7. The Just half of the red patches which $(7,8)$ count 179 equivalent to 0.635 was quality observed for Airtel as compared with MTN.

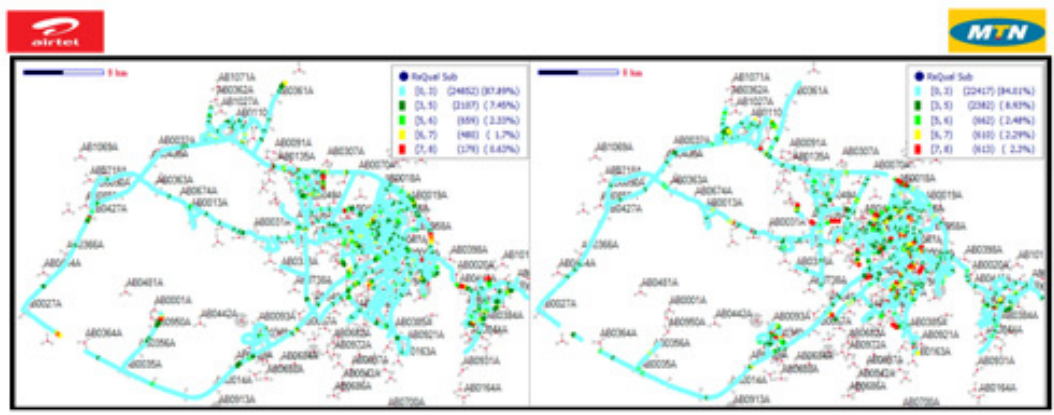

Figure 7: Performance of AITEL and MTN networks services for 2G Dedicated Mode

\subsection{Plot For Airtel And Glo 2G Dedicated Mode}

It is apparent from Figure 8, that Airtel quality was observed to be having better counts at $<=3$ when compared with GLO.

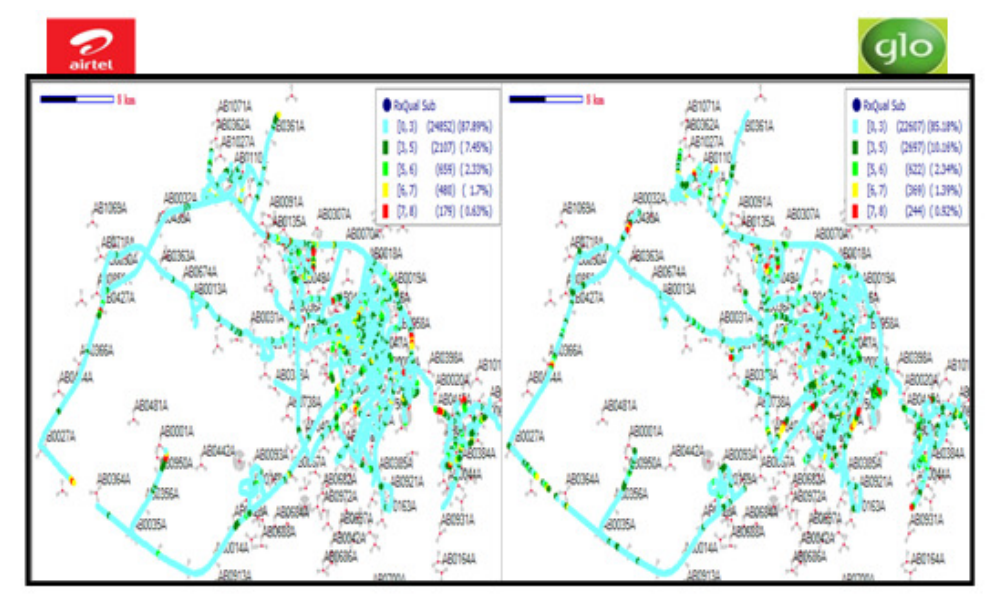

Figure 8: Plot for Airtel and Glo 2G Dedicated Mode

\subsection{Plot For Airtel And Etisalat 2G Dedicated Mode}

From Figure 9, it is observed data services provided by Airtel is to some extent better in terms of performance than the Etisalat as 24852 was recorded for Airtel as against 26531 for Etisalat. The handover success rate and dual band success rate are equally fair. 


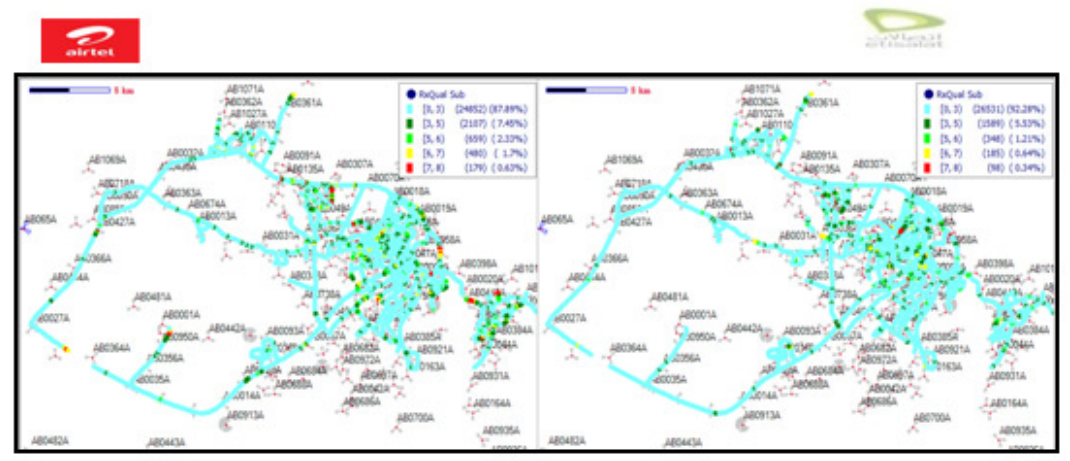

Figure 9: Plot for Airtel and Etisalat 2G Dedicated Mode

The 2Gnetwork competitive KPI events Abuja is shown in Table 1. From all test carried out, it was discovered as highlighted on the table that Airtel came first in all Key Performance Indicators (KPI) and coverage level. Except in Quality and Hand over Success Rate (HOSR) where Airtel came Second. Consequently, Airtel has very high performance compared to the values for the other three GSM providers. The handover success rate (both inter cell and dual band) improved. This shows that the concentration of bad handovers is localized where the network was down. Call success rate also improved on that same day. This enables the view of different KPI ranking at a glance.

Table 4.1: 2g Network Competitive Kpi Events-Abuja

\begin{tabular}{|c|c|c|c|c|c|c|c|c|c|}
\hline KPIS(Drive Test Dusa bused) & UNIT & AIRTEI. & Ranking & MTN & Ranking & C० & Ranking & EMTS & Ranking \\
\hline Rikev ( $2-85 \mathrm{shm})$ & $\%$ & 98.63 & $1^{ \pm}$ & 83.47 & $4^{4}$ & 97.86 & $2^{n t}$ & 90.65 & $3^{n}$ \\
\hline RrQual (0-5) & $\%$ & 95.73 & $2^{2}$ & 93.3 & $4^{2}$ & 95.69 & $3^{n}$ & 98.11 & $1^{*}$ \\
\hline SQI(16-30) & $\%$ & 9647 & $1^{*}$ & 91.07 & $3^{*}$ & 89.01 & $4^{4}$ & 9235 & $2^{24}$ \\
\hline SQI (23 to 30) & $\%$ & 8699 & $1^{x}$ & 80.17 & $2^{m a t}$ & 70.26 & $3^{\text {th }}$ & 0 & $4^{*}$ \\
\hline Call Drop rate & $\%$ & 22857 & $I^{ \pm}$ & 9.248 & $4^{\mathrm{a}}$ & 32.98 & $3^{4}$ & $2 \pi 3$ & $2^{\text {st }}$ \\
\hline Call Block rate & $\%$ & 1.1173 & $1^{*}$ & 3.621 & $2^{24}$ & 25.95 & $4^{4}$ & 5000 & $3^{t}$ \\
\hline HosR & $\%$ & 96.956 & $2^{\text {ed }}$ & 9557. & $4^{\mathrm{m}}$ & 96. 셩 & $3^{\mathrm{t}}$ & 98.42 & $1^{*}$ \\
\hline CSSR & $\%$ & \begin{tabular}{|l|}
98.883 \\
\end{tabular} & $1^{ \pm}$ & 9637 & $2^{2}$ & 74.04 & $4^{*}$ & 949 至 & $3^{t}$ \\
\hline Noosss Delay & Sec & 292 & & 295 & & 3.31 & & 3.04 & \\
\hline Call Attempt & Counts: & 358 & & 359 & & 655 & & 355 & \\
\hline Blocked Call & Counts: & 4 & & 13 & & 170 & & 9 & \\
\hline Call Fstablished & Counts: & 350 & & 346 & & 485 & & 337 & \\
\hline Call setup & Counts: & 354 & & 346 & & 485 & & 337 & \\
\hline Dropped Call & Counts & 8 & & 32 & & 16 & & 8 & \\
\hline Handover Attempted & Counts: & 1801 & & 1536 & & 1535 & & 1394 & \\
\hline Handover Fillure & Counts: & 55 & & 68 & & 54 & & 22 & \\
\hline Call Initiation & Counts: & 358 & & 359 & & 655 & & 355 & \\
\hline Call Find & Counts: & 342 & & 314 & & 469 & & 329 & \\
\hline Call Attempt Retry & Counts: & 12 & & 23 & & $z$ & & 18 & \\
\hline
\end{tabular}




\section{QOS FOR 3G IDLE MODE}

The study for QoS performance of the four service providers was investigated under $3 \mathrm{G}$ idle modes. Figure 10 depicts the performance of Airtel services provided with quality multiplemegabit internet services, and simultaneous voice and data access with multiple parties at the same time. Almost $37.62 \%$ accepted $3 \mathrm{G}$ radio standards are based on CDMA.

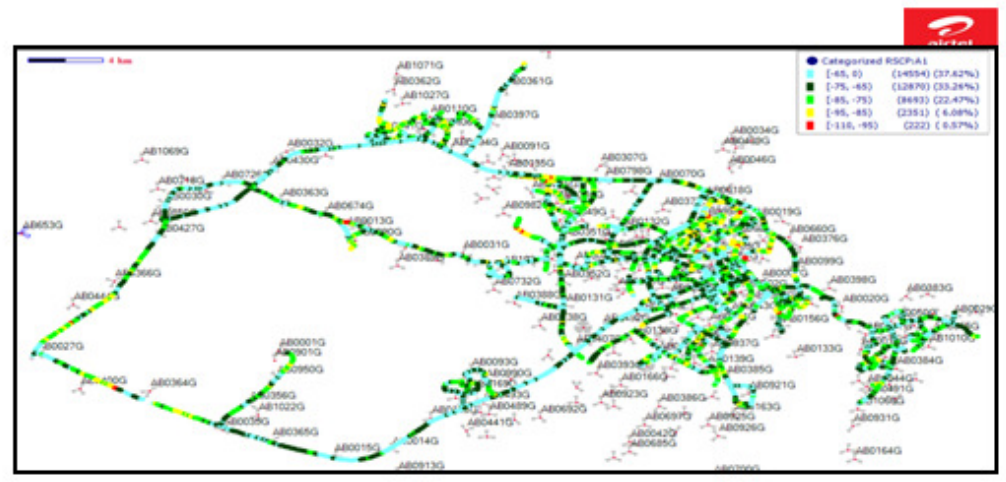

Figure 10: Performance of Airtel services

\subsection{AirTel AND MTN 3G IdLe Mode}

From Figure 11, it is observed that the Airtel 3G coverage was observed to have less bad patches when compared with MTN.

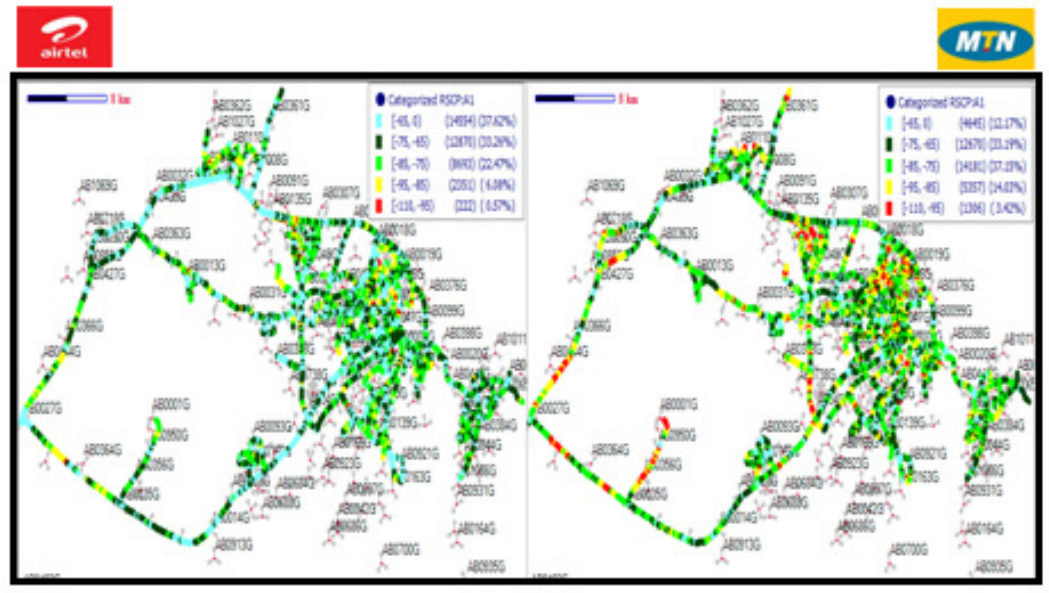

From Figure 11: Airtel and MTN 3G Idel Mode

\subsection{Airtel ANd Glo 3G IDle Mode}

From Figure 12 shows that, Airtel 3G coverage was observed to have $10.52 \%$ less bad patches when compared with GLO. 


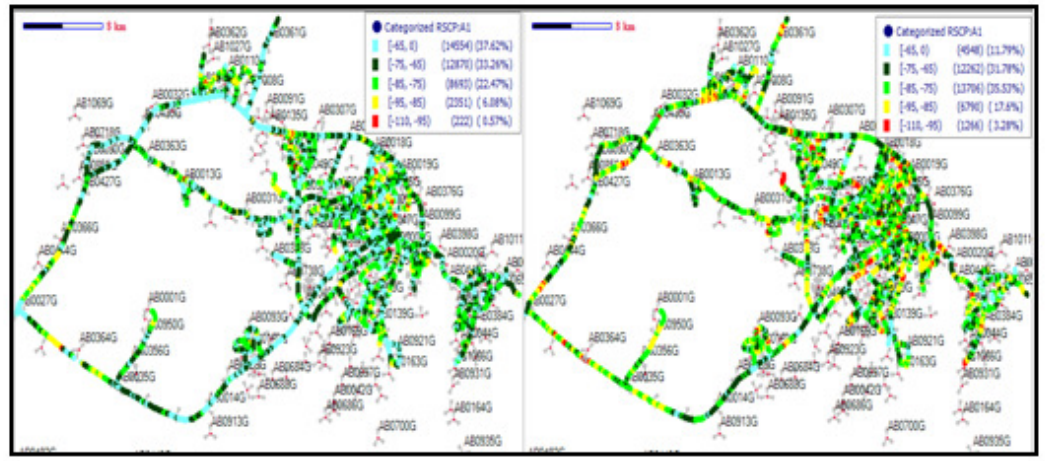

Figure 12: Airtel and GLo 3G Idle Mode

\subsection{Airtel And Etisalat 3G Idle Mode}

From Figure 13 shows that, Airtel 3G coverage was observed to have $37.62 \%$ better performance as compared to that of etisalat $12.72 \%$.

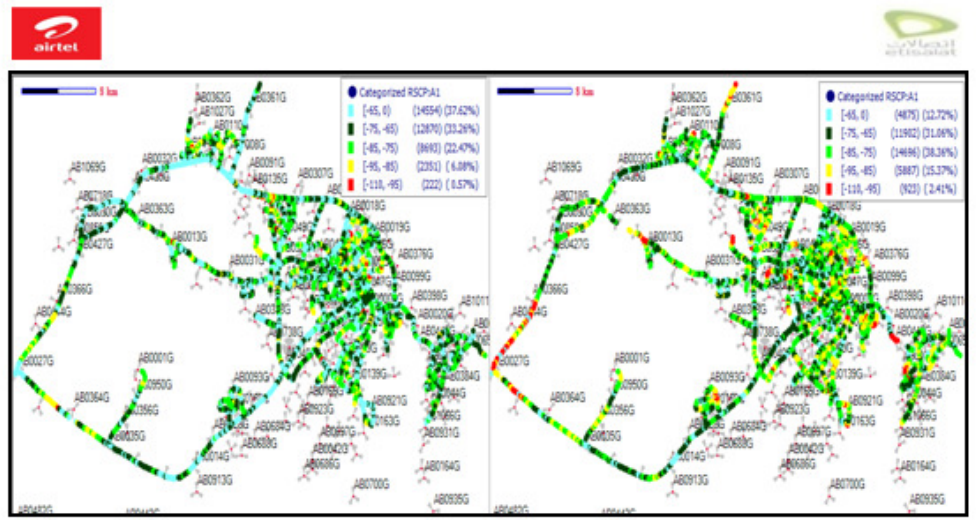

Figure 13: Airtel and Etisalat 3G Idle Mode

\section{3G DEDICATED MODE}

The $3 \mathrm{G}$ dedicate mode is design with a good differential mode transmission as shown in Figure 14. From the figure, Airtel $3 \mathrm{G}$ quality was observed to have less bad patches when compared with MTN, GLo and Etisalat.

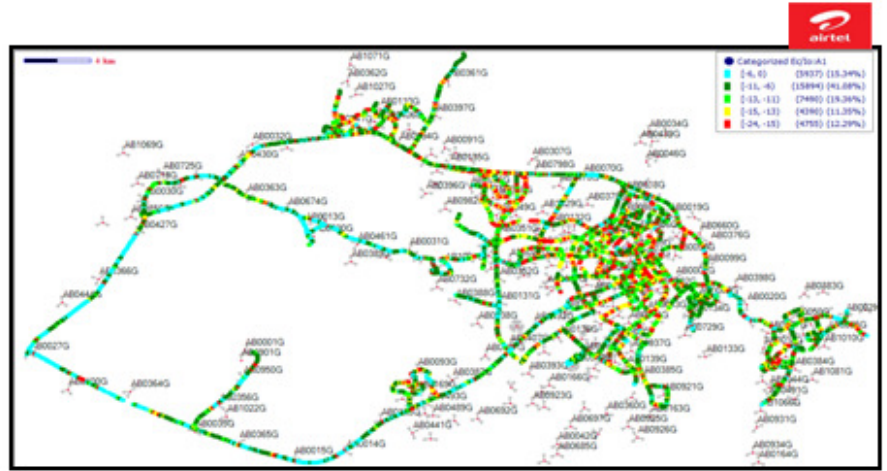

Figure 14: 3G Dedicated Mode 


\subsection{MATHEMATICAL EXPRESSION}

The mathematical expression in equation 1-4 shows how Call Set Up Success Rate (CSSR) is calculated which is among the KPI used in ranking performances of GSM.

a.

$$
\begin{aligned}
& \text { For Airtel, } \\
& C S S R=\frac{\text { call setup }}{\text { call attempt }} * 100 ; \quad \text { CSSR }=\frac{\mathbf{3 5 4}}{\mathbf{3 5 9}} * 100 \\
& C S S R=98.883 \%
\end{aligned}
$$

b. For MTN,

$$
\begin{aligned}
& \text { CSSR }=\frac{\text { call setup }}{\text { call attempt }} * 100 ; \quad \text { CSSR }=\frac{346}{359} * 100 \\
& \text { CSSR }=96.379 \%
\end{aligned}
$$

c. For Glo,

$$
\begin{aligned}
& \text { CSSR }=\frac{\text { call setup }}{\text { call attempt }} * 100 ; \quad \text { CSSR }=\frac{485}{655} * 100 \\
& \text { CSSR }=74.046 \%
\end{aligned}
$$

d. For Etisalat,

CSSR $=\frac{\text { call setup }}{\text { call attempt }} * 100 ; \quad$ CSSR $=\frac{337}{355} * 100$

\begin{tabular}{|c|c|c|c|c|c|c|c|c|c|}
\hline $\begin{array}{c}\text { KPIS } \\
\begin{array}{c}\text { (Drive Test Data } \\
\text { based }\end{array} \\
\end{array}$ & UNIT & $\underset{\mathrm{L}}{\mathrm{AIRTE}}$ & $\begin{array}{c}\text { Rankin } \\
\mathrm{g}\end{array}$ & MTN & $\begin{array}{c}\text { Ranki } \\
\text { ng }\end{array}$ & GLO & \begin{tabular}{|c|} 
Rankin \\
$\mathrm{g}$
\end{tabular} & EMTS & $\begin{array}{c}\text { Ranki } \\
\text { ng }\end{array}$ \\
\hline $\operatorname{RSCP}(>-95 \mathrm{dbm})$ & $\%$ & 99.43 & $1^{n t}$ & 96.54 & $4^{\prime \prime}$ & 96.70 & $3^{\text {rt }}$ & 97.51 & $2^{24}$ \\
\hline $\mathrm{EcNo}(=-11 \mathrm{db})$ & $\%$ & 56.42 & $1^{n t}$ & 39.88 & $4^{\prime \prime}$ & 44.22 & $3^{\text {rat }}$ & 44.30 & $2^{24}$ \\
\hline Call Drop rate & $\%$ & $\begin{array}{l}1.94805 \\
19\end{array}$ & $1^{n t}$ & $\begin{array}{c}8.71080 \\
1\end{array}$ & $4=$ & $\begin{array}{c}4.1769 \\
04\end{array}$ & $3^{\text {ra }}$ & 1.960784 & $2^{2 d}$ \\
\hline Call Block rate & $\%$ & $\begin{array}{c}0.64516 \\
13\end{array}$ & $1^{n t}$ & \begin{tabular}{|c|}
8.01282 \\
1
\end{tabular} & $3^{\text {rt }}$ & \begin{tabular}{|c|}
25.183 \\
82 \\
\end{tabular} & $4=$ & 2.547771 & $2^{n t}$ \\
\hline SHOSR & $\%$ & 100 & $1^{\text {t }}$ & 100 & $1^{\text {t }}$ & 100 & $1^{n t}$ & 100 & $1^{\text {t }}$ \\
\hline CSSR & $\%$ & 99.3548 & $1^{n t}$ & 91.987. & $3^{r a t}$ & 74.816 & $4=$ & 97.4522 & $2^{=4}$ \\
\hline Call Attempt & Counts & 310 & & 312 & & 544 & & 314 & \\
\hline Blocked Call & Counts & 2 & & 25 & & 137 & & 8 & \\
\hline Call Established & Counts & 308 & & 287 & & 407 & & 306 & \\
\hline Call Setup & Counts & 308 & & 287 & & 407 & & 306 & \\
\hline Dropped Call & Counts & 6 & & 25 & & 17 & & 6 & \\
\hline Call End & Counts & 306 & & 262 & & 390 & & 300 & \\
\hline Radio Link Addition & Counts & 720 & & 262 & & 260 & & 430 & \\
\hline Radio Link Removal & Counts & 622 & & 219 & & 209 & & 371 & \\
\hline $\begin{array}{c}\text { Radio Link } \\
\text { Replacement }\end{array}$ & Counts & 635 & & 45 & & 19 & & 41 & \\
\hline $\begin{array}{l}\text { Soft Handover } \\
\text { Attempts }\end{array}$ & Counts & 1977 & & 526 & & 488 & & 842 & \\
\hline $\begin{array}{l}\text { Soft Handover } \\
\text { Failure }\end{array}$ & Counts & 0 & & 0 & & 0 & & 0 & \\
\hline
\end{tabular}

$C S S R=94.93 \%$

\subsection{G NeTWORK COMPETITIVE KPI EVENTS}

Table 2 shows the 3G counts and ranking of Key Performance Indicator (KPI) of the four mobile networks. This enables the view of different KPI ranking at a glance.

Table 2: $3 g$ Network Competitive Kpi Events (Abuja) 
These inferred that Airtel took first position in all the KPI and coverage level. Table 3 illustrates the overview of the sample collected and Airtel Ranking for $2 \mathrm{G}$ and $3 \mathrm{G}$.

Table 3 Overview of 2G and 3G Key Performance Indicator on Voice

\begin{tabular}{|c|c|l|l|l|l|l|l|c|}
\hline \multirow{2}{*}{ Operator } & \multicolumn{4}{|c|}{ 2G VOICE KPI } & \multicolumn{4}{c|}{ 3G VOICE KPI } \\
\cline { 2 - 9 } & $\mathbf{D C R}$ & $\begin{array}{l}\text { RxQual } \\
\mathbf{0} \text { to 4) }\end{array}$ & $\begin{array}{l}\text { RxLevel(> } \\
\mathbf{- 8 5 d B M )}\end{array}$ & CSSR & DCR & $\begin{array}{l}\text { Ec Io } \\
(>-1)\end{array}$ & $\begin{array}{l}\text { RSCP(>- } \\
\text { 85dBM) }\end{array}$ & CSSR \\
\hline Airtel & 2.29 & 92.73 & 98.63 & 98.88 & 1.95 & 56.42 & 93.35 & 99.35 \\
\hline MTN & 9.21 & 90.05 & 83.47 & 96.38 & 8.71 & 39.88 & 82.51 & 91.99 \\
\hline GLO & 3.29 & 92.14 & 97.86 & 74.05 & 4.18 & 44.22 & 79.1 & 74.82 \\
\hline Etisalat & 2.37 & 96.3 & 90.65 & 94.93 & 1.96 & 44.3 & 82.14 & 97.45 \\
\hline $\begin{array}{c}\text { Airtel } \\
\text { Ranking }\end{array}$ & $\mathbf{1}$ & $\mathbf{2}$ & 1 & $\mathbf{1}$ & 1 & 1 & 1 & $\mathbf{1}$ \\
\hline
\end{tabular}

\subsection{RECOMMENDED REMEDIES FOR IDENTIFIED FAILURE}

From the above studies, the following identified failures /problems in $2 \mathrm{G}$ and $3 \mathrm{G}$ network and their recommended remedies are summarized in table 4 .

Table 4: Causes And Remedies For 2g Networks

\begin{tabular}{|l|l|}
\hline PROBLEM SUMMARY & RECOMMENDED REMEDIES \\
\hline Bad Patch & Restore Cell back on air. \\
\hline Coverage site not on air & Restore Cell back on air \\
\hline Adjacent Interference & Retune frequency \\
\hline Swap Sector & Cable tracing and swap sector correction will be done \\
\hline Missing Neighbor & $\begin{array}{l}\text { Neighbor plan required due to zero neighbor in the neighbor } \\
\text { list after new site installation }\end{array}$ \\
\hline Adjacent Interference & Retune frequency \\
\hline Overshooting Cell & Down Tilt Cell Site Antenna by $1^{\circ}$ Electrically \\
\hline
\end{tabular}

\section{ConClusion}

This study investigated the failures and remedies to GSM network in Abuja Nigeria. The aim is to provide better understanding to the GSM network as the network architecture. The GSM network which is divided into the three major systems comprises of the Switching System (SS), the Base Station System (BSS), and the Operation and Support System (OSS). The constants change and evolution of GSM network have necessitated the continuous optimization of the offered QoS. QoS is user oriented, while network performance (NP) is provider oriented. The subscriber will have a strong influence on the subjective perceived quality. The factor that really affects the QoS as perceived by the subscriber are the call set up delay and the end to end blocking, even though the QoS parameter are not always directly measured. In Nigeria, mobile network are leading the evolution of the information and communications society towards the MIS (Mobile Information Society). This means that subscriber numbers are continuing to increase as mobile penetration reached new heights. The network capacity tends to diminish as the network converge is improved considering the fact that the most valuable and limited resources of the capacity. In this project, the failures and remedies to GSM network were investigated; the impact of Channel state consistency, network performance, connectivity and interconnectivity on the performance of four GSM network providers. Analyses were made on failures that occurs on the GSM networks, to 
provide a deeper understanding of the QoS and Network Performance (NP) provided by the service providers to the subscribers.

TEMS Professional Phone w995 and TEMS Software v13.1 were used to survey and perform drive test for optimization of GSM network. The data collected were processed and analyzed using TEMS Discovery for percentage analysis and presented in tabular forms for better understanding.

Possible remedies to the problems were given; it should be noted that optimization solutions vary in different areas and networks but as discussed in this project the general approach can be developed to monitor and optimize the QoS as network continuously change in response to change in offered traffic and business priorities. It became obvious from this study that Airtel's GSM operations is far preferable than that of the three other GSM Operators, hence, they should borrow the technical approach of Airtel and improve their own operations.

\section{REFERENCES}

[1] Ajiboye, J. O., Tella, A., Adu, E. O., and Wojuola, J. I. (2016):“Stakeholders' Perceptions of the Impact of GSM on Nigeria Rural Economy: Implication for an Emerging Communication Industry, Journal of Mobile Communications, 3(1), 1-7.

[2] Amaldi, A.Capone, and F. Malucelli (2015): "Radio planning and coverage optimization of 3G cellular networks,"

[3] Andreas, P. and Ahmet, S. (2013):"Congestion Control: Book CI Congestion-Control-Final. (Tech. Doc.), University of Cyrus, Nicosia Cyrus. ITU-T Recommendation 1.371, (1993).

[4] Anton A. Huurdeman (2005), The Worldwide History of Telecommunications, John Wiley \& Sons, page 529.

[5] Hassan, O., Oluwaranti, N., and Isola, O. (2009), Evaluation of Nigeria's Telecommunications Policy, Journal of Mobile Communications, 3(1), 1-7.Ghaderi M., and Boutoba P., http://mobiles.tacticaltech.org/"

[6] Nishith E and Tripathi D., (1998) "Handoff in cellular systems" IEEE Personal Communication Magazine", pp. 26-37, 2010.

[7] Ojesanmi, O.A.; Oyebisi, T.O.; Oyebode, E.O. And Makinde, O.E., (2011).

[8] Performance Analysis of Congestion Control Scheme for Mobile Communication Network. International Journal of Computer Science and Telecommunications.

[9] Omotoye,K.O., Akogbe, M.A., Olaniyi, O.M. \& Inyiama (2015) H.C “Congestion Management on GSM networks using traffic Class Prioritizing”, international Journal of Engineering Research and Technology (IJERT),2014, Vol. 3, p474-478

[10] Pollioni G. P, (2012) “Trends in Handover Design”, IEEE Communications Magazine, Vol. 34, pp. 82-90, 2012.

[11] Shoewu, O and Edeko, F.O (2002), Outgoing Call Quality Evaluation of GSM Network Services In Epe", Lagos State, American Journal of Scientific and Industrial Research, Vol.2; pp. 409-417, 2011

[12] Ajala I. (2005), "GIS and GSM Network quality monitoring: A Nigeria case study (http://www.directionmag.com/ireti-GSM)" Retrieved 04-09-2016 14:22

[13] Alanko T. (1994), "Measure Performance of Data transmission Over GSM", University of Helsinki

[14] David Grill, (2014), Personal Communication and Traffic Engineering in ITU- T, Fondazion Ugo Bordoni.

[15] ETSI, GSM Specification Series 03.01-3.88, “GSM PLMN Functions, Architecture, Numbering and Addressing Procedures.” http://books.gogle.com. Retrieved 09/08/2016

[16] ETSI, GSM Specification Series 04.01-4.88, "MS-BSS Interface." http://books.gogle.com. Retrieved 09/08/2016

[17] ETSI, GSM Specification Series 06.01-6.32, "Radio Link." http://books.gogle.com. Retrieved 09/08/2016.

[18] ETSI, GSM Specification Series 08.01-8.60, "BSS-MSC Interface, BSC-BTS Interface. "http://books.gogle.com. Retrieved 09/08/2016.

[19] ETSI, GSM Specification Series 09.01-9.11, "Network Interworking, MAP.” http://books.gogle.com. Retrieved 09/08/2016. 
[20] Garg, V. K., and Wilkes, J. E. (2015), "Wireless and Personal Communication Systems, Prentice Hall", 2015.

[21] Jens Z. (2001), "Radio Resource Management for Pearson Education Ltd London"

[22] Kelly F. (1996), "Stochastic Networks Theory and Application", Oxford Science Publication, (http://www.statslab.ac.uk/Kelly/eb.html) Retrieved 10/08/2016.

[23] Pasi L. et al, (2005), "A Knowledge Based Model for Analyzing GSM Network Performance". (http://www.nokia foundation .com) Retrieved 10/08/2016.

[24] Pippikakis M. (2010):"Evaluation and Improving the Quality of Service of Second Generation Cellular System” (http://www.bechtel.com/technical/- journal/quality service) Retrieved 11/08/2016.

[25] Mouly M. et al (2013), "The GSM System for MobileCommunications, Mouly and Pautet Palaiseau", France, 2013.

[26] Terence Driscoll and Bod Dolden (2002): "Computer Studies and Information Technology", 1st Edition. NIIT Press, Oklahoma. Pp.1-6.

[27] V.E.Idigo, A.C.O.Azubogu, C.O.Ohaneme and K.A.Akpado (2012), "Real Time Accessment of QoS of Mobile Cellular Networks in Nigeria", International Journal of Engineering Inventions, Volume 1, Issue 6 (October 2012) PP: $64-68$. 